ISSN 2175-5361

UNIVERSIDADE FEDERAL DO ESTADO DO RIO DE JANEIRO - UNIRIO
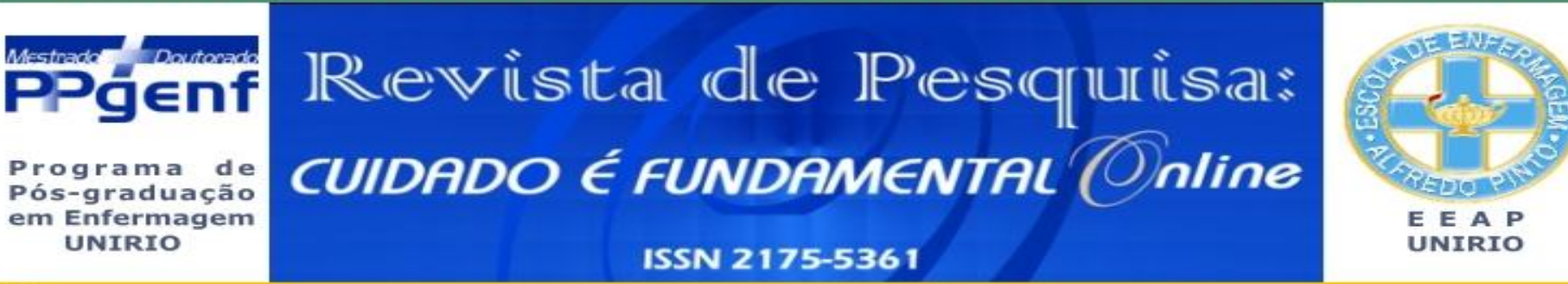

Ministério da Educação

PESQUISA

\title{
OLDEST OLD IN THE HOUSEHOLD: THE FAMILY AS UNIT OF CARE
}

IDOSOS MAIS VELHOS NO DOMICÍLIO: A FAMÍLIA COMO UNIDADE DE CUIDADO

LOS ANCIANOS MAYORES EN LA CASA: LA FAMILIA COMO LA UNIDAD DE CUIDADOS

Marinês Tambara Leite ${ }^{1}$, Julia Sperotto Flores ${ }^{2}$, Leila Mariza Hildebrandt ${ }^{3}$, Nara Marilene Girardon Perlini ${ }^{4}$, Caroline de Leon Linck $^{5}$

\begin{abstract}
Objective: The study aimed at analyzing how the family organizes itself as a unit of care to oldest old at the domiciliary space, based on the model Calgary Family assessment. Method: A qualitative, descriptive. The collection of data occurred through interviews, evaluating three family nuclei. Results: Based on the categories that make up the model and content analysis were analyzed aspects of the structure, development and functioning of families, including the socioeconomic dynamics of family organization, the role of the elderly and their influence on the familial relationship, the need for care, emotional and affective ties that (re) organize the family structure. Conclusion: The complexity of family relationships and ties that keep the elderly are essential to the preservation of their health, especially in aspects of care dependency. It is important to greater integration of the nursing team in this space in order to adapt to health care to the family organization. Descriptors: Family, Nursing, Modelo Calgary, Aged 80 and over.
\end{abstract}

\section{RESUMO}

OBJETIVO: O estudo objetivou analisar como a família se organiza enquanto unidade de cuidado a idosos mais velhos no espaço domiciliar, com base no Modelo Calgary de Avaliação Familiar. MÉTODo: Estudo de caráter qualitativo, descritivo. A coleta dos dados ocorreu por meio de entrevistas, avaliando três núcleos familiares. RESULTADOS: Baseados nas categorias que compõe o Modelo e na análise de conteúdo analisaram-se os aspectos da estrutura, desenvolvimento e funcionamento das famílias, abrangendo a dinâmica socioeconômica da organização familiar, o papel do idoso e sua influência na relação familial, a necessidade de cuidado, aspectos emocionais e vínculo afetivo que (re)organizam a estrutura familiar. CONCLUSÃO: A relação familiar e a complexidade dos vínculos que o idoso mantém são fundamentais para a preservação de sua saúde, especialmente nos aspectos relativos à dependência de cuidados. Considera-se importante maior inserção da equipe de enfermagem nesse espaço visando adequar a assistência em saúde à organização familiar. DESCRITORES: Família, Enfermagem, Modelo Calgary, Idoso de 80 anos ou mais.

\section{RESUMEN}

Objetivo: Este estudio tuvo como objetivo analizar cómo la familia está organizada como una unidad de cuidado de los ancianos en el hogar mayor, basado en el Modelo de Evaluación de la Familia de Calgary. Metodo: Estudio descriptivo cualitativo. Los datos fueron recolectados a través de entrevistas, la evaluación de cada tres hogares. Resultados: En base a las categorías que componen el modelo y el análisis de contenido se analizaron aspectos de la estructura, el desarrollo y funcionamiento de las familias, incluyendo las dinámicas socioeconómicas de la organización familiar, el papel de los ancianos y su influencia enla relación familiar, la necesidad de cuidado, los lazos emocionales y afectivos que (re)organizar la estructura de la familia. Conclusión: La complejidad de las relaciones familiares y los lazos que mantienen a las personas de edad son esenciales para la preservación de su salud, especialmente en los aspectos de la dependencia de cuidados. Es importante una mayor integración del equipo de enfermería en este espacio con el fin de adaptarse a la atención médica a la organización de la familia. Descriptores: Familia, Enfermería, Modelo Calgary, Anciano de 80 años o más.

${ }^{1}$ Enfermeira, Dra em Gerontologia Biomédica, docente da Universidade Federal de Santa Maria - Centro de Educação Superior do Norte do RS - UFSM/CESNORS. Tutora do Grupo PET Enfermagem/UFSM/CESNORS. E-mail: tambaraleite@yahoo.com.br. 2 Enfermeira, egressa do Curso de Enfermagem da Universidade Federal de Santa Maria/Centro de Educação Superior do Norte do Rio Grande do Sul. E-mail: juliasperotto.flores@gmail.com. 3 Enfermeira, Mestre em Enfermagem Psiquiátrica, docente da UFSM/CESNORS. E-mail: leilahildebrandt@yahoo.com.br. ${ }^{4}$ Enfermeira, Dra. em Enfermagem, docente da UFSM/CCS. E-mail: nara.girardon@gmail.com. ${ }^{5}$ Enfermeira, Mestre em Enfermagem, docente da UFSM/CESNORS. E-mail: carollinck15@yahoo.com.br. 
ISSN 2175-5361

\section{INTRODUÇÃO}

O envelhecimento é um processo temporal, para o qual a idade cronológica é um fator que contribui para sua ocorrência. Além disso, o fator biológico é decisivo, pois nele encontram-se as variáveis como a genética, o estilo de vida e o estado de saúde. Também se faz presente o fator social, no qual é considerada a participação na comunidade, o nível de independência e a condição econômica e cultural, o que torna esse processo único para cada indivíduo.

0 desafio inicial do envelhecimento populacional no Brasil está na demanda crescente por serviços de saúde, já que o envelhecimento, de maneira geral, propicia o aumento progressivo de doenças crônicas e degenerativas, que em sua maioria interferem na capacidade de independência pessoal e familiar, necessitam de uso contínuo de medicamentos e exigem cuidados ininterruptos e assistência de profissionais da saúde regularmente. ${ }^{1}$

Nesse sentido, para que a assistência seja efetiva há necessidade de enfrentar desafios, como a escassez de instituições de cuidado intermediário ao idoso no Sistema Único de Saúde (SUS), ou seja, estruturas de suporte qualificado para idosos e seus familiares com a finalidade de promover a intermediação segura entre a alta hospitalar e a ida para o domicílio. Essa responsabilidade gera implicações econômicas, sociais e culturais na organização e convívio familiar. $^{2}$

Entender que a família possa dar conta de assumir o cuidado da pessoa idosa é uma postura que pode ser considerada um tanto idealista, visto que a família vem sofrendo diversas modificações na sociedade atual e nem sempre tem condições de adotar responsabilidades complexas como, por exemplo, o cuidado do idoso que para isso, muitas vezes, exige que um membro da família deixe de trabalhar. $^{3}$
Por isso, a instituição familiar deve ser inserida no planejamento do cuidado do idoso. Esse cuidado deve assistir tanto as necessidades do idoso, quanto da família, afinal para a família manter um cuidado efetivo, ela deve estar saudável em sua organização. A atual estrutura familiar que, geralmente é multigeracional e com reduzido número de componentes, deve ser acolhida pela Estratégia de Saúde da Família, uma vez que essa é a porta de entrada da pessoa idosa na atenção básica, devendo criar em conjunto de ações de planejamento do cuidado do idoso e assistir as demais necessidades da família. Para tanto, é necessário avaliar e conhecer a cultura da família, os indivíduos que compõem sua estrutura e como se dá suas relações intra-familiares e sociais.

Nesse contexto, vale destacar que se entende a família como um grupo social que se constitui por um conjunto de pessoas, que possuem vínculos afetivo/efetivos podendo ou não ser ambíguos. Fruto da constituição social a qual se integra diferenciando cultural e socialmente. Considerada centro integral de convivência de pessoas onde às necessidades são providas pelos membros integrantes uniformemente de forma, a manter a representação social da família. ${ }^{4}$

Desse modo, se torna errôneo considerar uma família e suas relações, apenas ao que envolve seus parentescos consanguíneos. A unidade familiar, para os indivíduos que as constituem ultrapassa esse entendimento, afinal sua estrutura se firma mais sobre as relações emocionais e sociais, a quem eles recorrem em momentos de necessidade e compartilham os momentos de alegria entre os indivíduos, do que as relações de parentesco. Enfim, o que firma um grupo de pessoas como família, é a relação de apoio, seja esse emocional, educacional, financeiro ou social entre seus membros.

A família também pode ser entendida como um sistema, no qual um conjunto de 
ISSN 2175-5361

Leite MT, Flores JS, Hildebrandt LM et al. elementos se inter-relaciona. Assim, um sistema é uma entidade composta de pelo menos dois elementos e uma relação estabelecida entre cada elemento e pelo menos um dos demais elementos do conjunto. Cada um dos elementos de um sistema é ligado a todos os outros elementos, direto ou indiretamente. ${ }^{5}$ Para melhor compreender o conceito da teoria de sistemas aplicado à família, esta é comparada a um móbile. Assim como o móbile, a família é um todo composta de vários elementos ou membros. Uma mudança em um de seus membros afeta todo o grupo. Porém, a família tem habilidades para criar um balanceamento entre mudanças e estabilidade, de acordo com sua organização interior. $^{5}$

É essencial compreender a família como a mais constante unidade de saúde para seus membros. Assim, a assistência à família como unidade de cuidado implica em conhecer como cada família cuida e identificam suas forças, suas dificuldades e seus esforços para partilhar as responsabilidades. Com base nas informações obtidas, os profissionais devem usar seus conhecimentos sobre cada família, para junto dela, pensar e programar a melhor assistência possível. ${ }^{6}$

O genograma aparece como instrumento indicado para tal finalidade, já que é o diagrama do grupo familiar e detalha a estrutura e o histórico da família, além das condições de saúde de cada pessoa e a qualidade das relações entre seus membros. O Modelo Calgary, que fundamenta a utilização de genograma e do ecomapa para a avaliação de famílias pela enfermagem, vem sendo aplicado com sucesso, uma vez que por meio dele é possível compreender a dinâmica familiar e facilitar a aproximação entre o profissional e o usuário. ${ }^{5}$ Contudo, destaca-se que ainda são poucos os trabalhos publicados que relatam a experiência e implementação desse instrumento no campo da gerontologia.
Oldest old in the household...

Considerando os aspectos até aqui apontados este estudo tem como questão de investigação: De que modo a família se organiza como unidade de cuidado de idosos com mais de oitenta anos, ou seja, de idosos mais idosos no domicílio? E tem como objetivo analisar como a família se constitui em unidade de cuidado de idosos mais idosos no espaço domiciliar, com base no Modelo Calgary de Avaliação Familiar.

\section{O Modelo Calgary como referencial teórico- metodológico}

O modelo Calgary de Avaliação familiar foi publicado pela primeira vez em 1984, é uma adaptação da estrutura de avaliação da família desenvolvida por Tamm e Sanders em 1983. É definido pelos seus criadores como uma estrutura multidimensional integrada, baseada em sistemas, cibernética e fundamentos teóricos de mudanças e tem sido adotada em vários países como: Austrália Grã-Bretanha, América do Norte, Brasil, Japão, Finlândia, Suécia, Coréia e Taiwan. ${ }^{5}$

0 modelo avalia três categorias: estrutural, desenvolvimento e funcional, que se subdividem em três subcategorias. Na avaliação estrutural é necessário examinar quem faz parte da família, qual o vinculo afetivo entre seus membros em comparação com os indivíduos de fora e qual o seu contexto. Três aspectos da estrutura familiar especificamente podem ser examinados: a estrutura interna (que se subdivide em seis categorias), estrutura externa (divide-se em duas categorias), e o contexto familiar que é dividido em cinco categorias, como mostra o diagrama. A categoria desenvolvimento refere-se à transformação progressiva da história familiar durante as fases do ciclo de vida: sua história, o curso de vida, o crescimento da família, o nascimento e a morte. A avaliação funcional refere-se ao modo como os indivíduos da família interagem. Podem ser explorados dois aspectos: o funcionamento instrumental, que se refere às atividades da vida cotidiana, e o funcionamento 
ISSN 2175-5361

Leite MT, Flores JS, Hildebrandt LM et al. expressivo, que diz respeito aos estilos de comunicação, solução de problemas, papéis, crenças, regras e alianças. ${ }^{5}$

Para tal avaliação da família o Modelo Calgary utiliza dois diagramas: o genograma e o ecomapa, que facilitam a avaliação da estrutura familiar. Por meio deles é possível rapidamente visualizar as relações familiares e as fontes de informação, de forma sucinta, que podem ser utilizadas para o planejamento de estratégias de intervenção. Para ser eficaz devem ser construídos em conjunto com a família. O genograma demonstra a representação gráfica de dados sobre a família, e durante a sua construção há a visualização da dinâmica familiar e as relações entre seus membros, através de símbolos e códigos padronizados, em pelo menos três gerações. Permite, também, observar de forma clara quais membros constituem a família, tenham eles vínculos consanguíneos ou não. Desta forma, fornece bases para a discussão e análise das interações familiares. Os homens são representados por quadrados e as mulheres por círculos, identificando o nome, a idade, a profissão e doenças atuais de cada pessoa, além de retratar o lugar ocupado por cada um na estrutura familiar. Faz, ainda, com que a própria família identifique quais os membros que a integram e as relações estabelecidas entre si. ${ }^{5}$

O ecomapa é um diagrama das relações entre a família e a comunidade, que ajuda a avaliar as redes e apoios sociais disponíveis e sua utilização pela família. Mostra os contatos das famílias com pessoas, membros da família expandida, instituições ou grupos e, desse modo, a ausência ou presença de recursos sociais, culturais e econômicos de um determinado momento do ciclo vital da família, havendo modificação ao longo do tempo, portanto dinâmico. ${ }^{5}$ No ecomapa os membros da unidade familiar em questão são representados no centro do círculo. Já sua rede social aparece em círculos externos. As linhas indicam o tipo de conexão:
Oldest old in the household...

linhas contínuas representam ligações fortes, pontilhadas ligações frágeis, linhas tortuosas demonstram aspectos estressantes e as setas significam energia e fluxo de recursos. ${ }^{7}$

\section{METODOLOGIA}

Esta pesquisa caracteriza-se como qualitativa, com estudo de campo, de natureza descritiva. 0 estudo foi realizado em um município localizado na região norte do Estado do Rio Grande do Sul. A amostra foi do tipo intencional, em que as famílias foram selecionadas pela pesquisadora por considerar que estas possuem características representativas da população e, em função da importância que elas têm em relação ao tema eleito. ${ }^{8}$ Para compor a amostra estabeleceram-se como critérios de inclusão: ser uma família que tenha entre seus integrantes uma pessoa idosa com 80 anos ou mais morando no mesmo espaço doméstico; que uma pessoa idosa seja a responsável pelo cuidado do idoso mais idoso; pelo menos um dos integrantes da unidade familiar tivesse condições cognitivas de ser entrevistado; estar residindo na área de abrangência da Unidade Básica de Saúde (UBS), local sorteado para a localização das famílias.

A obtenção dos dados foi balizada pelo Modelo Calgary de Avaliação Familiar, com a elaboração do genograma - representação gráfica dos membros da família e seus relacionamentos, a avaliação do desenvolvimento da família ao longo do ciclo vital, com suas tarefas e vínculos, do funcionamento instrumental e expressivo. ${ }^{5} 0$ membro da família que tem idade acima de 80 anos e que é cuidado foi considerado a pessoa índice. Assim, foi realizada a avaliação de três famílias, em que foram entrevistados 09 integrantes. Para tanto, realizou-se três visitas a cada família, no período de julho a setembro de 2011. Na primeira visita ocorreu o contato inicial entre entrevistadora e a família, momento que foi 
ISSN 2175-5361

Leite MT, Flores JS, Hildebrandt LM et al.

explicado o objetivo do trabalho e seu desenvolvimento. Os integrantes da família presentes ao concordar assinaram o termo livre esclarecido e, na sequência, houve o agendamento dos próximos encontros. No segundo encontro foi elaborado o genograma familiar em conjunto com os entrevistados. Na terceira visita foi realizada a entrevista com a família, versando sobre as relações entre a família e a comunidade, que foi gravada e, posteriormente, transcrita. Após o término das visitas foi elaborado pelo pesquisador o ecomapa de cada família.

Após a coleta das informações estas foram organizadas e analisadas, com base nos preceitos da análise de conteúdo, seguindo suas etapas: préanálise, a qual é a fase da organização e sistematização das idéias iniciais; exploração do material, que consiste na codificação, desconto ou enumeração, em função de regras previamente formuladas; e por fim, tratamento dos resultados, a inferência e interpretação, na qual os resultados são tratados de maneira a serem significativos e válidos. ${ }^{9}$

Com o objetivo de atender os preceitos éticos nas pesquisas que envolvem seres humanos o projeto de pesquisa foi aprovado pelo Comitê de Ética em Pesquisa da Universidade Federal de Santa Maria/UFSM, Parecer Consubstanciado $n^{\circ}$ 0084.0.243.000-11. No intuito de preservar o anonimato, cada família foi codificada com o nome de uma constelação, Três Maria, Ursa Maior e Andrômeda, e seus membros receberam a denominação das estrelas que estão agrupadas nesses coletivos.

\section{RESULTADOS E DISCUSSÃO DOS DADOS}

\section{Apresentando as famílias}

As três famílias possuem residência própria e estão localizadas próximas a Unidade Básica de Saúde, na qual estão cadastradas como usuárias. A renda mensal de cada família varia de três a sete salários mínimos. As pessoas índices são do sexo
Oldest old in the household...

masculino, estão aposentadas como trabalhador rural e frequentaram o ensino formal por até três anos. Nas três famílias, o familiar responsável pelo cuidado ao idoso mais idoso é do sexo feminino.

\section{Família Três Maria}

Avaliação estrutural

A família é mononuclear, composta por três pessoas idosas, sendo que duas delas têm mais de 80 anos de idade. Quanto ao gênero, encontra-se Alnilan, do sexo masculino, viúvo, 82 anos de idade, alfabetizado, agricultor, aposentado, com renda mensal de um salário mínimo, natural de Palmeira das Missões/RS. Reside com a atual companheira há 20 anos - Mintaka, 75 anos de idade, divorciada do primeiro casamento há 40 anos, possui o ensino médio, é professora aposentada, tem renda mensal de dois salários mínimos, é natural de Barreiro/RS. Anterior a união do casal, ela residiu por 10 anos com a senhora Alnitaka, de 87 anos, do sexo feminino, alfabetizada, aposentada, com renda de um salário mínimo. Embora não tenha laços consaguíneos com Mintaka, permanece residindo no mesmo domicílio que o casal, convivência essa que soma 20 anos.

A estrutura externa da família é representada pelos filhos do primeiro casamento do casal e seus descendentes e está ilustrada na figura 1. Mintaka teve dois filhos. Uma filha que faleceu e um filho que reside fora do Estado do Rio Grande do Sul. Alnilan possui 6 filhos, que também moram fora do Estado. Os filhos os visitam com pouca frequência, cerca de uma vez por ano, mas eles afirmam conhecer todos os netos e bisnetos, que no caso de dona Mintaka são o maior "xodó" referindo-se a estes últimos. Refere, ainda, sentir muito não poder ficar perto deles. Além da família extensa, a estrutura externa desta família conta ainda com sistemas mais amplos como, os vizinhos, as festas da sociedade, a comunidade religiosa a qual pertencem e a Estratégia Saúde da Família. 
ISSN 2175-5361

Leite MT, Flores JS, Hildebrandt LM et al.

0 ambiente em que estão inseridos está, de certa forma, adaptado as necessidades dos idosos. A residência tem estrutura mista, alvenaria e madeira, possui sete cômodos, tem acesso a energia elétrica e saneamento básico rede de água, esgoto e recolhimento de lixo. Seu interior é mobiliado com móveis e eletrodomésticos que proporcionam adequado conforto para a família. A casa é cercada, possui calçamento e conta com uma horta e um pomar. A via pública de acesso a residência não é pavimentada. Nenhum dos moradores da casa se ocupa com os afazeres domésticos, uma vez que estes são realizados por uma pessoa contratada.

Um dado que chama a atenção diz respeito às condições ambientais e de produção dos alimentos, pois há plantação de hortaliças e árvores frutíferas suficientes para o consumo da família. Isto possibilita aos integrantes uma alimentação saudável, redução de custos financeiros e, consequentemente, melhora nas condições de saúde.

\section{Avaliação de desenvolvimento}

A família encontra-se em um único estágio que é o definido como final de vida pelo fato de os filhos terem constituído novas famílias e pela idade avançada. As atividades realizadas pelos integrantes das famílias consistem em conversar com as vizinhas. Mintaka também se ocupa produzindo artesanato e, quando vai para a área rural, frequenta festas de igreja e salões paroquiais, locais onde joga bingo. É católica e no primeiro dia da entrevista relatou estar muito feliz, pois era aniversário de 20 anos de união com seu Alnilan. Em função desse tempo o padre permitiu que mesma comungasse. Também, estava viabilizando uma forma de pedir ao Ministro da Igreja, para o mesmo levar a comunhão em sua casa para o esposo, já que este não tem condições físicas de ir até a igreja. Lembra que este local era frequentado semanalmente antes de seu adoecimento. Isso
Oldest old in the household...

demonstra o apego aos aspectos da religião, além de ser a principal forma de inserção na comunidade, evidenciando o significado da aprovação de sua união conjugal.

Quanto à assistência a saúde, a família informa que o vínculo ocorre por meio da Estratégia da Saúde da Família (ESF) e se limita a consultas médicas e a imunizações previstas nas campanhas de vacinação. Neste caso uma técnica de enfermagem se desloca até a residência e administra o agente imunológico. Menciona, ainda, que não recebem visita e atualmente seu Alnilan encontra-se com problemas de audição e, devido a condição clínica, está inseguro e amedrontado, segundo sua esposa, uma vez que está com medo de morrer. Antes do diagnóstico de insuficiência cardíaca congestiva, costumava cuidar da chácara junto com o filho e jogar carta com os amigos da terceira idade, mas após seu adoecimento prefere permanecer em casa, na companhia de da sua esposa e vizinhas que se reúnem diariamente para tomar mate.

Destaca-se que é importante o acompanhamento pela equipe de saúde a esta família, uma vez que as condições clínicas, especialmente do Sr. Alnilan, requerem assistência constante. Como exemplo, em uma das visitas da pesquisadora, a mesma identificou que o mesmo apresentava hipotensão e bradicardia, encaminhando-o para consulta médica na ESF, de onde ele foi, posteriormente, para internação hospitalar.

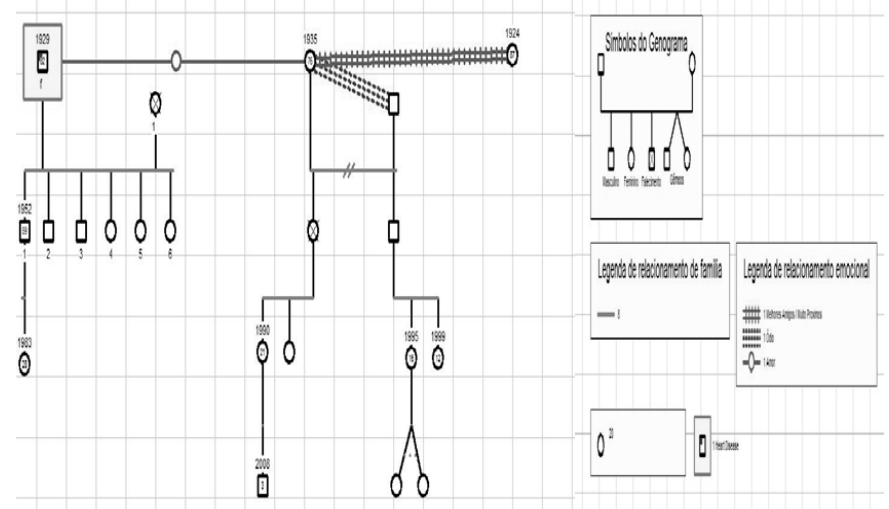

Figura 1: Genograma da família Três Maria 
ISSN 2175-5361

Leite MT, Flores JS, Hildebrandt LM et al.

\section{Família Ursa Maior}

Avaliação Estrutural

A família Ursa Maior é formada por sete membros: Merake, o patriarca, Dubhe, filha mais velha, com seu esposo Megres. O casal tem três filhos (Alioth, Benetnasch e Pechta) e o neto Mizar. Assim, sua composição é classificada com uma família ampla. A pessoa índice, seu Merake, tem 82 anos de idade, sexo masculino, divorciado há 30 anos, portador de diabetes Mellitus tipo II, aposentado, pai de 12 filhos, sendo 11 do casamento. Possui casa própria de alvenaria, localizada próxima a de seus filhos. Mesmo assim, reside com a filha mais velha, Dubhe, por motivos de dependência parcial para a realização das atividades da vida diária, decorrente de complicações da doença, neuropatia periférica, que o levou a perder parcialmente a sensibilidade e força motora dos membros inferiores. Condição que dificulta sua deambulação e, também, em função de segurança, já que fora assaltado duas vezes.

A estrutura externa da família conta com o apoio dos outros filhos de Merake, este estudou até a quarta série e, antes de se aposentar, era capataz de fazendas e trabalhou em diversos locais no País. Retornou para sua cidade natal, a pedido dos filhos, há, aproximadamente, 15 anos, quando teve o diagnóstico de Diabetes Mellitus. Toda assistência médica que recebe é oriunda da Estratégia Saúde da Família, na qual é cadastrado.

Para o tratamento e acompanhamento que não está disponível na ESF, conta com o auxílio financeiro dos filhos que fazem uma "vaquinha" $e$ realizam o pagamento necessário. Caso a mãe deles, ex-esposa de Merake, precise os filhos também prestam a assistência necessária. 0 controle glicêmico e dietético é realizado por Dubhe, que afirma sempre preparar dois tipos de refeições: um para a família e outro para o seu pai.

A maioria dos filhos de Merake tem o ensino fundamental concluído. Segundo Dubhe ele
Oldest old in the household...

pode não ter sido um pai muito presente e não participou diretamente da educação deles, mas nunca deixou faltar nada em casa. Merake relata manter bom relacionamento com os filhos e, frequentemente, se reúne com toda a família, já que a maioria mora na cidade. Embora ele não se interesse muito pela filha fora do casamento, esta tem uma relação amistosa com os irmãos e sempre que possível entra em contato. Merake tem conflitos com sua ex-esposa e mesmo que seja sua vizinha não fala com ele há 20 anos. Assim, sempre que os filhos se reúnem devem escolher se convidam o pai ou a mãe para participar dos encontros. Além da ex-esposa, ele também relatou sentir-se ignorado por sua filha Akor, que não aceitou o adultério do pai.

Os sistemas amplos de convivência e apoio social que a família está inserida são a ESF e a Associação de Pais e Amigos dos Excepcionais (APAE) como está ilustrado na figura 2. 0 ambiente em que o idoso está inserido é uma casa, na qual a família Ursa Maior reside, pertencente a seu genro Megres, que trabalha como eletricista. 0 seu Merake fica instalado em um quarto no fundo da casa, ao lado da cozinha, e durante o inverno passa as manhãs dormindo e as tardes tomando chimarrão. Quando se sente bem e com condições para caminhar, sai passear, encontrar os amigos e jogar na lotérica, caso contrário permanece em casa ouvindo radio. A casa é de madeira, possui sete quartos, tem acesso a energia elétrica e saneamento básico rede de água, esgoto e recolhimento de lixo. Em seu interior é mobiliada com móveis e eletrodomésticos que proporcionam adequado conforto para a família. A residência possui um pequeno pátio, algumas flores e uma área para o cultivo de hortaliças. É cercada com uma cerca de madeira, não possui calçada e localiza-se em uma via pública sem calçamento. 
ISSN 2175-5361

Leite MT, Flores JS, Hildebrandt LM et al.

\section{Avaliação de desenvolvimento}

Com a inserção do avô e tendo os filhos e netos no mesmo espaço domiciliar a família encontra-se em dois estágios do ciclo familiar: estágio tardio de vida ou estágio seis e em transição no estágio cinco. A família divide-se para desempenhar as atividades rotineiras como Dubhe que se ocupa dos afazeres domésticos e do cuidado de seu neto, enquanto sua filha Benetnasch sai para o trabalho. Pechta, a filha mais nova de Dubhe, voltou recentemente para casa, após muita insistência da mãe, depois de ter passado uma temporada na casa de tios na região metropolitana da capital, onde trabalhava. Alioth, sexo masculino, é aluno da APAE e lá passa o período das tardes, nas aulas e oficinas oferecidas.

Os vínculos externos da família estão relacionados com 0 gosto por festas, porém sempre estão atentos, pois Dubhe não pode ingerir qualquer dose de bebida alcoólica, hábito que ainda não foi abandonado pelos outros membros da família, inclusive seu Merake. A figura 2 apresenta a estrutura familiar da família Ursa Maior:

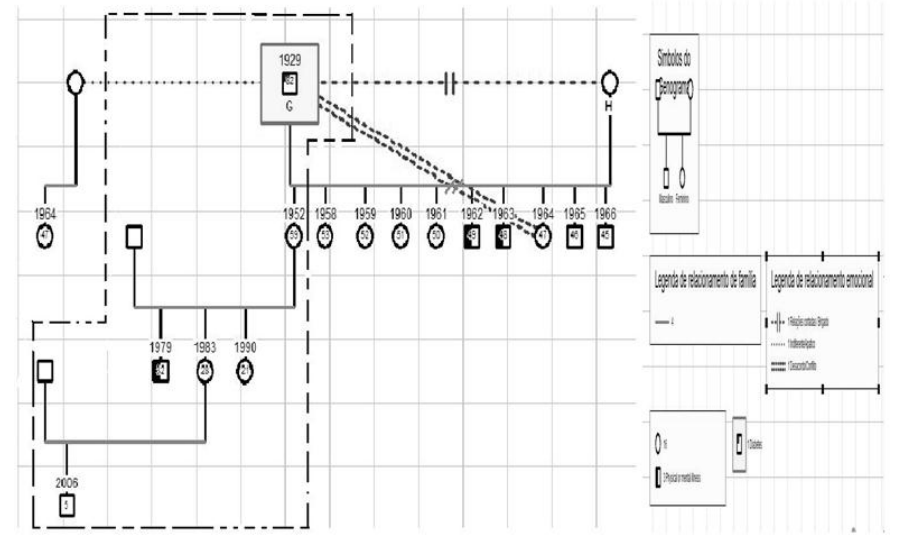

Figura 2: Genograma da Família Ursa Maior

\section{Família Andrômeda}

Avaliação estrutural

A composição da família Andrômeda consiste em cinco membros residentes no mesmo espaço domiciliar, estes são o Sr. Alpheratz, com 93 anos de idade, e seus dois filhos: Mirach, sexo feminino, 61 anos de idade e Chi Andromedae, sexo masculino, 46 anos de idade, que possui
Oldest old in the household...

doença mental (Esquizofrenia) e fica sob os cuidados de Mirach. Além desses, residem na casa uma neta - Gama And, de 22 anos de idade e um bisneto de 15 anos, Almak que reside com a família desde o falecimento do pai (filho de Mirach) e da união da mãe com outra pessoa. Assim, o grupo pode ter sua composição classificada como família extensa. A casa pertence ao esposo de dona Mirach, que reside em uma cidade vizinha em razões de trabalho.

A estrutura externa da família compõe-se principalmente dos filhos de Mirach que, embora não morem no mesmo local frequentemente a visita. O médico da Estratégia da Saúde da Família, que visita Alpheratz comumente pode ser considerado uma das poucas redes amplas de apoio, juntamente com alguns amigos da família como é representado na figura 5. Contudo, eles afirmam não gostar dos outros funcionários da ESF, a exceção de uma técnica de enfermagem que, segundo dona Mirach, nunca os esquece.

0 ambiente no qual o idoso está inserido se resume a residência da família que tem estrutura de madeira com três cômodos e o banheiro encontra-se na parte externa na casa. 0 quarto de Alpheratz é uma área anexa a casa, que é abastecida por água encanada, porém não tem acesso a rede de esgoto e de recolhimento de lixo. Destaca-se que o lixo é separado, o que é orgânico utilizam para alimentar os animais e os demais resíduos é depositado em um terreno longe da casa, ato realizado, também, por outros vizinhos. A casa localiza-se em um terreno extenso, onde a família cria alguns animais domésticos como galinhas, bezerro e cavalo.

\section{Avaliação de desenvolvimento}

Pelas características familiares já descritas, pode-se dizer que a família encontra-se em dois estágios do ciclo familiar: etapa tardia da vida, identificada pela presença do idoso, viúvo e com filhos casados, e família com adolescentes, pela presença do bisneto. 
ISSN 2175-5361

Leite MT, Flores JS, Hildebrandt LM et al.

As atividades desenvolvidas pela família no espaço domiciliar giram em torno de Alpheratz, que é viúvo há 10 anos. Quando a esposa vivia, moravam na área rural do município, em uma chácara que hoje fica sob os cuidados do esposo de sua neta. Como não tinha condições de morar sozinho escolheu ir residir junto com sua filha mais velha. Alpheratz é dependente parcial de cuidados, uma vez que realiza as atividades básicas da vida diária com limitações, além de ter dificuldades na fala (disfonia), devido a problemas na dentição. Também apresenta restrições para deambular, pois afirma ter a memória prejudicada e, por isso, tem medo de sair e se perder ou de ser assaltado, fato que já ocorreu. Assim, suas atividades diárias são tomar chimarrão, coordenar e delegar as funções do trato dos animais e das tarefas da casa.

Mirach não frequentou o ensino formal, recentemente aprendeu a escrever o nome, com o auxílio de uma nora que é professora. Diz não ter estudado porque desde pequena teve que trabalhar e ajudar sua família. Casou-se aos 14 anos, atitude essa que considerava normal na época, já que seus pais não tinham condições de cuidar de toda família. Embora não tenha uma forte relação afetiva com seu esposo, refere ter sorte, pois juntos tiveram cinco filhos, construíram a casa deles e não passam necessidades. De todos os filhos apenas a mais nova estudou até a oitava série do ensino fundamental, esta também é a única solteira e sem filhos. É ela a responsável pelos cuidados do avô Alpheratz. O auxilia para banhar-se, vestir-se e alimentar-se. Ela, também, trabalhava cuidando de outra pessoa idosa, namorada de Alpheratz, amiga da família, que faleceu recentemente.

Chi Andromedae, filho de Alpheratz, foi acolhido por Mirach, após viver por muito tempo na rua. Tem doença mental e, segundo Mirach, sua principal cuidadora, é muito violento. Faz uso de medicamentos psicotrópicos, que o deixa dormindo o dia todo. Além dele, ainda, reside na

R. pesq.: cuid. fundam. online 2012. out./dez. 4(4):2816-31
Oldest old in the household...

casa Almak, do qual o bisavô fala com muito orgulho. Ele tem 15 anos e foi morar com os avós após o falecimento do pai, em um acidente de trânsito, fato ainda não superado por Mirach, que se emociona ao falar do filho. Almak é quem mais acata as ordens de Alpheratz, sendo o responsável pelos animais da propriedade e o principal companheiro dele, quando não está estudando. A avó, Mirach, fala com orgulho do neto, pois este nunca teve problema na escola e está economizando para que ele possa estudar em um colégio técnico existente na cidade.

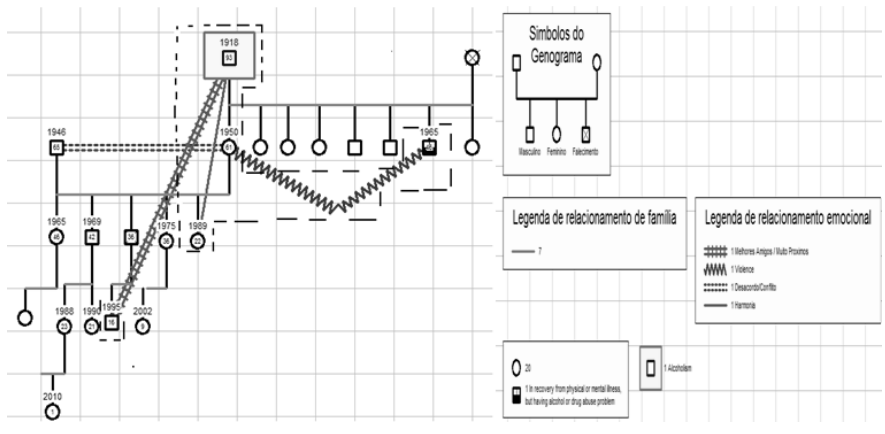

Figura 3: Genograma da Família Andrômeda

A partir da leitura e análise das informações produzidas, resultado das entrevistas e construção de genograma, foi possível aglutinar o conteúdo em duas categorias de análise. A primeira versa sobre a dinâmica socioeconômica das famílias, a segunda aborda a necessidade de cuidado, os aspectos emocionais e o vínculo afetivo, condições que (re)organiza a estrutura familiar e acerca das questões hierárquicas construídas historicamente pelas famílias.

\section{Dinâmica socioeconômica na organização familiar \\ Identifica-se que a situação} socioeconômica das famílias, que constituem o presente estudo, possibilita que as mesmas mantenham boas condições de vida. Isso ocorre porque as famílias dos idosos possuem moradia própria e uma renda assegurada, vinda da previdência social, além de terem alternativas de sustento, como no caso das famílias Três Maria e Andrômeda, que produzem boa parte de sua alimentação. Já a família Ursa Maior possui renda 
ISSN 2175-5361

Leite MT, Flores JS, Hildebrandt LM et al. extra que provem do aluguel de imóvel. Estas condições, aliadas as economias feitas no passado, permitem que os idosos não tenham necessidade de trabalhar para auxiliar na renda da família. Desse modo, para as três famílias a entrada da pessoa idosa no convívio do lar não afetou a situação econômica da família. Como disse Mintaka da família Três Maria: “Eu sempre guardei um pouco do meu dinheiro para quando precisasse... ninguém nunca sabe se vai precisar, principalmente em caso de saúde. E agora que eu preciso, eu tenho. Eu agora tenho que descansar, já que trabalhei muito".

Embora estejam vinculados aos serviços de saúde pública, no caso a Estratégia da Saúde da Família, as famílias referem que, ainda, a principal preocupação financeira é relacionada com as questões da saúde dos idosos. Na família Ursa Maior Dubher diz: "Tem coisas para o tratamento do pai que a gente não consegue ali no posto. Às vezes nem tem também. Tipo no início do ano o pai precisava de um tratamento diferente e do 'aparelhinho da diabete, não tinha, daí meus irmãos ajudaram com o que podiam e compramos, afinal é o pai”. Isso mostra também a cooperação familiar, que mesmo tendo a delegação dos cuidados a uma família, todos os demais se corresponsabilizam, de alguma forma, para manter a assistência mais adequada.

A família se constitui em uma unidade de apoio, solidariedade de reprodução social e de cuidados a seus integrantes. Esse espaço de proteção social é circunscrito e restrito, diferente da proteção social pública, que é generalizada e universalizada. Destaca-se que a capacidade de apoio da família à pessoa idosa está, cada vez mais, menor, especialmente em virtude das novas configurações familiares. ${ }^{10}$ Além disso, outra característica importante, dos idosos que continuam sendo os provedores de suas casas, é que eles não perdem a função de contribuintes para a sociedade e se auto valorizam. ${ }^{11}$
Oldest old in the household...

Os idosos aposentados constituem uma parcela da sociedade com maior estabilidade, e aumenta o número de casos nos quais eles são os responsáveis pelo sustento de suas famílias. Encontrando-se com boa saúde, os menos favorecidos economicamente, realizam trabalho informal, recebendo baixos rendimentos, mas ganham também amizades, domínio no domicílio e liberdade financeira. Igualmente, ele passa a ser visto como um trabalhador e não como um aposentado, o que thes confere o poder e o status de provedor, inserido na vida familiar e, por conseguinte, afastado da segregação. ${ }^{12}$

Uma parcela considerável dos idosos tem a necessidade de assegurar não só a própria manutenção, mas a sobrevivência de sua família. ${ }^{12}$ Pesquisa mostra que a participação do idoso na renda familiar se revela cada vez mais expressiva, uma vez que na década de 1980, a contribuição dos idosos era de 37\%; já, em 1990, passou a ser 47,2\% e, em 2007, em 53\% dos domicílios com idosos do país, mais da metade da renda era fornecida por pessoas com 60 anos ou mais. ${ }^{13}$

A constatação de que as famílias que possuem idosos coabitando a mesma residência têm renda maior se comparado a outras famílias, pode se explicar em função do tipo de arranjo familiar e das fases do ciclo familiar, que estabelecem ou não relações de dependência entre os integrantes da família. ${ }^{14} \mathrm{Em}$ muitas famílias, filhos, netos, noras e genros, irmãos e até cunhados encontram amparo sob o benefício do idoso aposentado que, mesmo não recebendo um grande valor, comumente consegue fornecer algum tipo de ajuda. ${ }^{15}$

\section{Necessidade de cuidado, aspectos emocionais $e$ o vínculo afetivo (re)organiza a estrutura familiar \\ Com o processo de envelhecimento,} ocorrem mudanças biológicas, sociais e culturais que aumentam as dificuldades dos idosos para preservar sua autonomia. Em função das 
ISSN 2175-5361

Leite MT, Flores JS, Hildebrandt LM et al.

alterações econômicas e, por vezes, da necessidade de amparo, os idosos buscam formas de (re)organizar a estrutura familiar de tal modo que possibilite, ao máximo possível, cultivar sua identidade e, ao mesmo tempo, conviver com outras gerações e culturas diferentes.

Assim, as famílias multigeracionais vivenciam, simultaneamente, duas fases de estágios do ciclo de vida familiar: a família com filhos pequenos e a família em estágio final da vida. $^{3}$ Essa característica se refere à estrutura familiar em relação ao tempo, sendo que a vida de uma geração cria impacto modelador nas gerações subseqüentes. ${ }^{16}$ Desse modo, em um mesmo espaço de tempo e dentro de uma mesma organização familiar existem ao menos três gerações vivendo situações e necessidades diferentes, sendo que essas mudanças, frequentemente, são pessoais no ciclo de vida.

O contato entre gerações diferentes de uma mesma família e seus vínculos afetivos são o equilíbrio da própria sociedade, que consiste em encontrar o meio-termo entre identidade e diferença, envolvimento e distância, autonomia e solidariedade das gerações, criando, do mesmo modo, uma rede de apoio intrafamiliar. ${ }^{17}$ Nesse contexto, identifica-se que não existe uma organização familiar padrão, e as três famílias deste estudo evidenciam isto, já que encontraram formas diferentes de conviver com seus membros e com a própria comunidade. Modos de viver que, a princípio, deram certo. Assim, os arranjos sociais adotados por essas famílias são frutos da escassez de condições materiais de vida e sociais, e se tornam possíveis devido ao exercício de uma forma democrática de organização familiar.

A enfermagem, responsável pelo cuidado, orientação e avaliação das relações de saúde da população de modo em geral, deve se apropriar e conhecer a dinâmica familiar principalmente no que se trata de sua organização para planejar e intervir (se necessário) no processo de saúde, não apenas do individuo, mas come de toda a família.
Oldest old in the household...

A Política de Atenção Básica defende que é função da enfermagem o “cuidado familiar ampliado, efetivado por meio do conhecimento da estrutura e da funcionalidade das famílias que visa propor intervenções que influenciem os processos de saúde-doença dos indivíduos, das famílias e da própria comunidade". ${ }^{18}$

Destaca-se que o familiar responsável pelo cuidado ao idoso dependente merece atenção especial. Todavia, mesmo havendo um integrante do grupo familiar que assuma a maior parte dos cuidados do idoso, toda a família deve ser, de alguma forma, mobilizada e envolvida na situação, de acordo com as possibilidade e viabilidade de cada um, mas favorecendo uma atenção de qualidade. É importante que os familiares dos idosos sejam vistos como indivíduos que requerem necessidades particulares e necessitam de auxílio para que possam realizar a tarefa de cuidadores na situação de adoecimento crônico de seu familiar idoso. ${ }^{19}$

Na família Três Maria, os três membros se conheceram já idosos e escolheram morarem juntos, pois acreditavam que assim teriam mais autonomia e, como diz Mintaka: "Nós cuidamos de nós mesmos, temos a nossa casinha, cada um tem o seu dinheiro e tem os vizinhos também". Embora ela e o companheiro Alnilan tenham filhos, netos e bisnetos, só mantém contato direto com uma neta mais velha dele, a única que ainda reside no município. Já, a outra integrante, Alnitaka, não tem nenhum familiar e, consequentemente, as únicas pessoas com quem convive, além dos que coabitam a residência, são os vizinhos. Ela assim se manifesta: “A gente faz tudo sozinho, eu que arrumo meus remédios. Quando eu preciso vou ao postinho, só tem a moça que limpa a casa, lava a roupa e fica comigo quando os outros 'velhos' saem. O resto é tudo a gente que cuida". Por essa fala fica evidente a autonomia e, também, o orgulho de serem independentes para a realização das atividades da vida diária. 
ISSN 2175-5361

Leite MT, Flores JS, Hildebrandt LM et al.

A tendência dos idosos de não migrarem para a casa de seus filhos, não revela necessariamente o enfraquecimento das relações familiares, mas sim uma escolha individual desses idosos. O bem-estar na velhice não está diretamente relacionado à intensidade das relações familiares, especialmente se os idosos e seus filhos possuem um grau de autonomia física e econômica que possibilite a manutenção da privacidade de ambos os lados. ${ }^{20}$

Em contrapartida, nas outras famílias a necessidade de cuidados e vínculos afetivos levou os idosos a irem para perto de seus familiares, ocasionando mudanças no estilo de vida tanto dos idosos, como das outras gerações que residem no mesmo ambiente. Como afirma Dubher da família Ursa Maior ao ser questionada porque seu pai está residindo com ela: “Já arrombaram a casa do pai duas vezes, ele não dava certo com ninguém para morar com ele (empregada, acompanhante), ele tava lá no meu irmão, ele ficou com fraqueza nas pernas, foi atrás de ajuda, mas não conseguia nem se arrastar, foi achar ele três dias depois, daí ele mandou me chamar para eu cuidar dele e ficar aqui comigo". Ao ser questionado do porque entre todos os filhos ele escolheu Dubher, Merake afirma: "É que ela sempre está por casa, os outros trabalham fora ou vivem longe e ela cuida bem de mim, nunca me disse nada, sempre me tratou bem".

A mesma pessoa também revela medo de ficar sozinho, ou até sair sozinho depois da violência que sofreu e afirma que na casa da filha se sente mais seguro, principalmente quando o neto o acompanha para sair de casa. Embora não tenha uma relação afetiva com os netos e bisnetos, a neta Pechta diz " $O$ vô dá uns agrados para a gente (dinheiro) quando a gente faz alguma coisa pra ele. Assim dá para eu comprar minhas coisinhas" fato que não acontecia quando seus filhos eram jovens. Dubher diz "Tudo que a gente tinha a gente conseguia trabalhando, o pai dava casa, comida e educação, o resto era com a
Oldest old in the household...

gente”. Essa reação também é vista na família Andrômeda em que a filha também afirma que os netos dela se dão melhor com o bisavô que os filhos dele, e ele é mais carinhoso como avô do que foi como pai.

Com a queda da fecundidade, da natalidade, com o aumento da longevidade, a urbanização e a industrialização, projetava-se que os ninhos vazios aumentassem, em virtude da diminuição dos integrantes da família. Contudo, as famílias mais carentes não se enquadram nessa condição, uma vez que elas comumente são numerosas, coabitam o mesmo espaço doméstico com várias gerações - pais, filhos, netos - como tática de sobrevivência. É nesse ponto de vista que as famílias assumem para si o cuidado necessário a seus membros e, consequentemente, havendo co-residência nas quais os beneficiados em algumas condições são os idosos e em outras os seus descendentes. ${ }^{10}$

Essa relação entre as gerações distantes também foi constatada em pesquisa com idosos que eram o alicerce financeiro de suas famílias. ${ }^{12}$ A autora afirma que os próprios filhos reconhecem que os idosos são referências para os mais jovens, principalmente os que coabitam a mesma residência. Além da relação de carinho, os netos vêem os avôs como exemplo de vida, pelo esforço e trabalho que desempenharam até então, e seguem a risca os conselhos como é o caso do bisneto da família Andrômeda, que segundo a avó não faz nenhum serviço em casa sem saber a opinião do bisavô, que o tem como referência de companheiro e cuidador: "O neto sempre me leva onde eu quero e faz tudo que eu gosto, até dobra os 'paieiros'(fumo) pra mim, mas eu já dei o recado para ele, que ele pode enrolar, mas não pode pitar".

Uma maior afetividade demonstrada para com os netos do que com os próprios filhos também ocorre na família Três Maria em que Mintaka afirma sentir mais falta dos netos que dos filhos: “É sempre bom ter crianças por perto e os 
ISSN 2175-5361

Leite MT, Flores JS, Hildebrandt LM et al. meus filhos já são crescidos tem a vida deles, já os pequenos estão sempre fazendo a gente rir".

Isso ocorre porque com os netos os avós geralmente não têm a responsabilidade de educálos, assim, a cobrança fica a cargo dos pais, enquanto o carinho é dado pelos avós.

Os netos ocupam um lugar de destaque no discurso dos avós, cujo desejo é fazer por eles o que não puderam fazer pelos filhos. Além disso, as gerações mais velhas, nunca tiveram o exercício de demonstrar seus sentimentos e/ou pensamentos para seus filhos, afinal eram os chefes de casa. E depois dos filhos crescidos, de certa forma perderam o pouco do vinculo afetivo familiar, permanecendo antes de tudo o respeito pela figura paterna dos filhos. Desse modo, a reaproximação do pai como avô da família do filho permite ao idoso expressar suas emoções de forma dinâmica recriando os laços de afetividade com seus filhos e fortalecendo sua relação com seus netos. $^{12}$ A questão intergeracional é um ponto importante a ser trabalhado pelos profissionais da saúde, em particular pelos enfermeiros, em relação ao cuidado para com os idosos e sua família, pois, se por um lado a relação entre os mesmos traz consigo muitos conflitos, por outro, pode ser considerada um processo de ajuda mútua. $^{21}$

Outra característica que se destaca é o fato de que o principal familiar responsável pelo cuidado é do sexo feminino nas três famílias, sendo que em duas delas é a filha primogênita. As mulheres assumem essa tarefa, pois é uma consequência da trajetória e história familiar, predominando a ideia de reciprocidade, em que a mesma assume a responsabilidade com base no respeito mútuo e na generosidade recíproca. ${ }^{22}$

Essas características são claras na fala de Dubher, ao ser questionada se houveram mudanças no serviço da casa depois que seu pai foi morar no mesmo domicílio, ela afirma “Um pouco, já que a comida eu tenho que sempre tá fazendo dois tipos: pra ele e outra pro resto do
Oldest old in the household...

pessoal. Mas no resto ele se vira sozinho, só de manhã cedinho que eu tenho que acordar mais cedo pra fazer o teste do dedo, o resto pra mim é igual, dá trabalho nenhum não'.

0 que também contribuiu para que as mulheres fossem as cuidadoras, foi o fato das mesmas já desempenharem o trabalho no espaço doméstico. Salienta-se que os integrantes idosos dão a entender que as tarefas do lar não se constituem em trabalho e não requerem muito tempo, condição que possibilita o cuidado dos pais, como no caso do idoso da Família Andrômeda quando afirma: “Eu vim pra cá porque os outros filhos todos trabalham e ela fica em casa, daí tem mais tempo pra me ajudar".

Em relação à presença feminina no cuidado ao idoso mais velho, entende-se que isto se constitui em uma ação que se reproduz historicamente e culturalmente. Isto é, o cuidar sempre foi uma prerrogativa da mulher, enquanto que ao homem cabia a tarefa de prover o sustento econômico do lar. A origem da palavra cuidado possui duas significações básicas e ligadas entre si: a primeira tem a conotação de atitude, de desvelo, de solicitude e de atenção para com o outro e a segunda consiste em uma preocupação e inquietação advindas do envolvimento e da ligação afetiva com o outro por parte da pessoa que cuida. Historicamente, a figura masculina tinha o cuidado de manter o sustento de sua família, a figura feminina era responsável pelo cuidado com os membros da mesma. ${ }^{23}$

As questões relativas ao cuidado, exercido predominantemente por mulheres, são visíveis não apenas culturalmente e historicamente, uma vez que desde que o cuidado se caracterizou como uma ação e uma ciência, por meio da prática e do ensino de enfermagem, é notável a presença da maioria feminina nessa área. Entretanto, da mesma forma com que as mulheres passaram a se inserir em diferentes áreas de atuação no mercado de trabalho, os homens recentemente também 
ISSN 2175-5361

Leite MT, Flores JS, Hildebrandt LM et al. estão se inserindo na área da enfermagem e, portanto, realizando ações de cuidado.

Além disso, identifica-se, por parte dos idosos, certa desvalorização do trabalho realizado no ambiente doméstico pelas integrantes do grupo familiar do sexo feminino. Essa condição emergiu nos relatos das famílias que compõem o presente estudo, em especial, naquelas em que os pais residem com as filhas. Quanto a isso, assim Merake se manifesta: “É que ela não trabalha. Tem só o serviço de casa, os outros todos têm seus serviços, ela só cuida da casa, já tem os filhos grandes que podem se virar, daí ela pode me ajudar para o que eu precisar".

Na família Três Maria também há um relato de que as mulheres se submetem e aceitam o costume masculino. Como exemplo disso, para atender o patriarca da casa, a alimentação é preparada privilegiando sua preferência. Desse modo, Alnitaka diz “Aqui tudo é pra ele, ainda mais que está doente (...) antes a comida já tinha que ser do jeito dele, senão coitada da empregada, já tinha que ouvir... e tudo que ele gosta é dele, se faz um doce e ele não come primeiro já fica emburrado e uns dois dias sem falar com a gente!".

Assim percebe-se que a presença feminina, no ambiente domestico, é o principal fator que contribui, para que as mulheres sejam as principais referências de cuidado desses idosos, além de que culturalmente, já lhes havia sido destinada essa atividade.

\section{CONSIDERAÇÕES FINAIS}

Este estudo buscou analisar como a família se constitui em unidade de cuidado de idosos mais velhos no espaço domiciliar, com base no Modelo Calgary de Avaliação Familiar. Ao entender que a família se compõe como a principal fonte de cuidado, é relevante desenvolver estudos que contemplem o espaço doméstico, cujos resultados possam balizar as intervenções relativas à saúde
Oldest old in the household...

com foco na família, em especial, naquelas que possuem idosos em situação de fragilização.

É importante mencionar que as famílias estudadas são compostas por idosos, sendo a renda constituída pela aposentadoria dos idosos que compõe o núcleo familiar, evidenciando que não há dependência financeira por parte da pessoa idosa. Nessas famílias identifica-se que os idosos mais velhos são dependentes de cuidados, em decorrência de patologias e por problemas emocionais. Visualiza-se, nas famílias, uma relação multigeracional, a qual tem dois aspectos: um positivo, pois fortalece os laços familiares, se constitui em um espaço de troca de experiências e, consequentemente, de aprendizado, já que os mais velhos estão inseridos no mundo dos jovens, no caso netos, e esses aprendem valores de família e responsabilidade para com os avós. Porém, esse ambiente poderá favorecer para aumentar a dependência do idoso de seus familiares, principalmente para a realização das atividades instrumentais da vida diária, pois há uma tendência de o idoso deixar, ou ser impedido, de fazer tarefas que comumente fazia.

Os idosos entrevistados, embora não desempenham atividade laboral, não se sentem desestimados pelos familiares, ao contrário, entendem que a necessidade de residir com seus filhos e/ou necessitar de cuidados em função de sua condição de saúde/doença, faz parte do processo de envelhecimento, e acreditam ser bom conviver com seus familiares, contato que antes não tinham tão frequentemente.

Entende-se que há necessidade da inclusão dos serviços de saúde no espaço familiar para adequar a assistência à saúde na organização familiar. Salienta-se que, no contexto estudado, os integrantes das famílias estabelecem e mantém vínculos de afeto e de gratidão, o que favorece para que o familiar cuidador tenha satisfação em realizar as ações de cuidar da pessoa idosa, que pode estar mais ou menos dependente de cuidado. 
ISSN 2175-5361

Leite MT, Flores JS, Hildebrandt LM et al.

Por fim percebe-se que o papel da enfermagem na atuação junto à família é o de reforçar a capacidade que esta tem de atender e suprir as necessidades e cuidados da pessoa idosa mais velha, sendo na verdade uma fonte de apoio à família e não a demovendo da capacidade e competência para desempenhar o papel de principal cuidador.

\section{REFERÊNCIAS}

1. Jacob Filho W, Gorzoni ML. Geriatria e gerontologia: o que todos devem saber. São Paulo; Roca; 2008, 288 p.

2. Brasil. Política Nacional de Saúde da Pessoa Idosa, Portaria $n^{\circ} 2.528$ de 19 de outubro de 2006.

3. Silva L, Galera ASF, Moreno V. Encontrando-se em casa: uma proposta de atendimento domiciliar para famílias de idosos dependentes. Acta paul. enferm. 2007; 20(4): 397-403.

4. Lacerda MR O cuidado transpessoal de enfermagem no contexto familiar. Revista Cogitare Enfermagem. 1997; 2(1): 44-49.

5. Wright LM, Leahey M. Enfermeiras e famílias: um guia para avaliação e intervenção na família. $4^{a}$ ed. São Paulo: Roca; 2008.

6. Angelo $M$, Bousso RS. Fundamentos da assistência à família em saúde. Manual de enfermagem [online]. Disponível: http:www.ids-saude.org.br/enfermagem.

7. Pereira APS, Teixeira GM, Bressan CAB, Martini JG. O genograma e ecomapa no cuidado de enfermagem em saúde da família. Revista Brasileira Enfermagem, Brasília, 2009; 62(3): 407-16.

8. Turato ER. Tratado da metodologia da pesquisa clínico-qualitativa. Petrópolis RJ: Editora Vozes, 2003.

9. Bardin L. Análise de conteúdo. Lisboa: Edições 70, 2011.
Oldest old in the household...

10. Teixeira SM. Família e as formas de proteção social primária aos idosos. Revista Kairós, São Paulo, 2008; 11(2): 59-80.

11. Santos AA, Pavarin SCl. O genograma para caracterizar a estrutura familiar de idosos com alterações cognitivas em contexto de pobreza. Revista Mineira de enfermagem, 2009; 13(4): 525-533.

12. Coutrin MRE. Idosos trabalhadores: perdas e ganhos nas relações intergeracionais. Sociedade e Estado, 2006; 21(2): 367-390.

13. Brasil. Instituto Brasileiro de Geografia e Estatística (IBGE). Censo demográfico 2010. Características da população e dos domicílios: resultados do universo. Disponível em: http://www.ibge.gov.br/home. Acesso em: 15 de nov. 2011.

14. Alcântara AO, Debert GG. Família e velhice: revisitando mitos e certezas. In: Congresso Brasileiro de Sociologia, 13, 2007, Recife-Pe. Família e velhice: entre mitos e certezas, 2007.1(-): 1-3.

15. Augusto HA, Ribeiro EM. O idoso rural e os efeitos das aposentadorias rurais nos domicílios e no comercio local: 0 caso de Medina, nordeste de Minas. In: Encontro Nacional de Estudos Populacionais, 15, ABEP, realizado em Caxambu/MG, Brasil, de 18-22 de setembro de 2006.

16. Carter B, McGoldrick M. As mudanças no ciclo de vida familiar - Uma estrutura para a terapia familiar. Porto Alegre, RS: Artes Médicas, 1995.

17. Brito HS. Estresse, resiliência e vulnerabilidade: comparando famílias com filhos adolescentes na escola. Rev Bras Crescimento Desenvolv Hum. 2006;16(2):25-37.

18. Brasil. Ministério da Saúde. Portaria n. 648/GM, de 28 de março de 2006. Brasília: Ministério da Saúde; 2006. [citado em 25 nov 2007]. Disponível em: http://dtr2001.saude.gov.br/sas/portarias/Por t2006/GM/GM-648.htm. 
19. Montezuma CA, Freitas MC, Monteiro ARM. A família e o cuidado ao idoso dependente: estudo de caso. Revista Eletrônica de Enfermagem [on line]. 2008;10(2):395-404. Disponível em: http://www.fen.ufg.br/revista/v10/n2/v10n2a 11.htm.

20. Debert GG. Família, classes sociais e etnicidade: um balanço da bibliografia sobre a experiência de envelhecimento. BIB, Revista Brasileira de Informação Bibliográfica em Ciências Sociais, Rio de Janeiro, n.33, p.33-49, $1^{\circ}$ semestre, 1992.

21. Sousa RF, Skubs T, Bretas ACP. Envelhecimento e família: uma nova perspectiva para o cuidado de enfermagem. Revista Brasileira de Enfermagem, 2007; 60(3):263-7.

22. Horta AL, Ferreira DC. Envelhecimento, estratégias de enfrentamento do idoso e repercussões na família. Revista Brasileira de Enfermagem, 2010; 63(4):523-8.

23. Zoboli ELCP. A redescoberta da ética do cuidado: o foco e a ênfase nas relações, Rev Esc Enferm USP, 2004; 38(1):21-7.

Recebido em: 21/04/2012

Aprovado em: 02/08/2012 